\title{
Presença, estrutura, morte: Derrida leitor de Husserl
}

\author{
Presence, structure, death: Derrida reader of Husserl
}

\author{
Daniel Guilhermino* \\ daniel.guilhermino@usp.br \\ (Universidade de São Paulo, São Paulo, Brasil)
}

\begin{abstract}
Resumo: 0 artigo tematiza a interpretação da doutrina da significação de Husserl que Derrida elabora em $A$ Voz e o Fenômeno e a contrasta com a doutrina semiótica das Investigações Lógicas. Para tanto, dois argumentos são levantados com respeito à análise de Derrida sobre a relação entre signo e coisa e entre signo e morte. O objetivo é mostrar que as conclusões de Derrida não se seguem das premissas de Husserl. Com isso, pretendese, minimamente, não só problematizar a "desconstrução" enquanto modelo de leitura de textos filosóficos, como também trazê-la ao debate propriamente filosófico.
\end{abstract}

Palavras-chave: Derrida; Husserl desconstrução; signo.

\begin{abstract}
The paper discusses Derrida's interpretation of Husserl's doctrine of meaning in Voice and Phenomenon and contrasts it with the semiotic doctrine of the Logical Investigations. To this end, two arguments are raised with respect to Derrida's analysis about the relation between sign and thing and between sign and death. The aim is to show that Derrida's conclusions do not follow from Husserl's premises. With this, it is intended, at least, not only to problematize "deconstruction" as a model for reading philosophical texts, but also to bring it into the philosophical debate itself.
\end{abstract}

Keywords: Derrida; Husserl; deconstruction; sign.

\section{Introdução}

Derrida publica A Voz e o Fenômeno - Introdução ao problema do signo na fenomenologia de Husserl em 1967. O propósito deste pequeno ensaio é, declaradamente, "analisar a doutrina da significação tal como se constitui desde a primeira das Investigações Lógicas" (Derrida, 2012, p.9, nota 2, meu grifo). Longe de elaborar uma reconstrução sistemática do movimento expositivo do texto husserliano, porém, Derrida procura desvelar uma série de decisões implícitas que supostamente comandariam as descrições e distinções fenomenológicas que ali se apresentam. Essas decisões recebem o carimbo de “metafísica da presença” - um título que,

\footnotetext{
* Bolsista da Fundação de Amparo à Pesquisa do Estado de São Paulo (FAPESP). Processo n 2019/01444-6.
} 
o que quer que signifique, parece possuir uma clara conotação pejorativa. Essa exposição da doutrina da significação husserliana movida por um intento de desvelar os prejuízos fundadores do autor é tida como um modelo daquilo que ficou conhecido como desconstrução de textos filosóficos. Em Gramatologia, Derrida sublinha que

os movimentos de desconstrução não solicitam as estruturas do fora. Só são possíveis e eficazes, só ajustam seus golpes se habitam estas estruturas. Se as habitam de uma certa maneira, pois sempre se habita, e principalmente quando nem se suspeita disso. Operando necessariamente do interior, emprestando da estrutura antiga todos os recursos estratégicos e econômicos da subversão, emprestando-os estruturalmente, isto é, sem poder isolar seus elementos e seus átomos, o empreendimento da desconstrução é sempre, de um certo modo, arrebatado pelo seu próprio trabalho (Derrida, 1973, p.30).

Embora seja, portanto, um empreendimento imanente ao texto filosófico, sua intenção é, certamente, ir além: “a desconstrução não pode limitar-se ou passar imediatamente a uma neutralização: deve, por um duplo gesto, uma dupla ciência, uma dupla escrita, praticar uma inversão da oposição clássica e um deslocamento geral do sistema” (Derrida, 1991, p.372). Como afirmam Bernet e Brown (1982, p.89, meu grifo), "as diferenças metafísicas devem permanecer indecididas, a tensão entre o que é dito no interior do texto e o não-dito que foi excluído do texto não deve ser neutralizada, mas antes acentuada". ${ }^{1}$

A recepção deste trabalho (inaugural da desconstrução) de Derrida foi tão ampla quanto diversa. Tal recepção foi compilada por Evans (1991). De um lado, Rorty escreve que "Derrida realiza um trabalho de primeira classe e altamente profissional sobre Husserl” (1989, p.207 apud Evans, 1991, p. xi), e Gadamer fala da "crítica bem acurada às Investigações Lógicas de Husserl e ao seu conceito de Kundgabe, desenvolvida no belo livro A Voz e o Fenômeno" (1989, p.95, apud Evans, ibidem.). De outro, temos Searle afirmando que "muitos dos argumentos de Derrida são simplesmente horríveis" (Searle, 1983, apud idem, ibidem, p.xii) e que se trata de um

baixo nível de argumentação filosófica, de uma prosa deliberadamente obscurantista, afirmações descontroladamente exageradas, e o esforço contínuo para dar uma aparência de profundidade ao fazer afirmações que parecem paradoxais, mas que, sob análise, frequentemente se mostram bobas ou triviais (1984, p.48, apud idem, ibidem).

Especificamente sobre o texto em questão, John Scanlon afirma que a "pequena e estranha peça intitulada $A$ Voz e o Fenômeno pode ser lida, justificadamente, como uma paródia sofisticada de uma exegese pomposamente pedante do primeiro capítulo da Primeira Investigação Lógica”, e que "construir argumentos elaborados

1 Todas as traduções para o português de qualquer obra que não utilizei a tradução (Cf. Bibliografia) são de responsabilidade minha. 
para mostrar conclusivamente que essa pequena e estranha peça distorce os textos de Husserl seria como construir um argumento elaborado para mostrar que é errado comer crianças irlandesas de um ano" (Scanlon, apud idem, ibidem).

Não pretendo construir argumentos elaborados para mostrar que Derrida distorce Husserl; mas pretendo, sim, seguir minimamente o fio-condutor de sua interpretação (uma vez que ela é assumidamente imanente ao texto) e a contrastar com o texto das Investigações Lógicas.

O objetivo de Derrida é ambicioso, e sua chave de leitura se condensa na afirmação de que "uma leitura paciente faria aparecer nas Investigações a estrutura germinal de todo o pensamento de Husserl” (Derrida, 2012, p.9). Derrida enxerga na distinção entre índice (Anzeichen) e expressão (Ausdruck), da Primeira Investigação, a pré-figuração da distinção fenomenológica geral entre fato e essência; e na redução à vida solitária da alma (einsamen Seelenleben), a pré-figuração da redução à subjetividade transcendental. ${ }^{2}$ São essas distinções da Primeira Investigação que principalmente denunciariam a adesão inconsciente de Husserl à metafísica da presença (adesão que acompanharia, portanto, toda sua filosofia). Para Derrida, no entanto, "é o próprio Husserl que nos dá os meios para contra ele mesmo pensar" (idem, p.57), e esses meios serão buscados principalmente na sua teoria da significação da percepção e na teoria das significações essencialmente ocasionais. Esses meios husserlianos serão utilizados não só para apresentar uma tensão no centro da fenomenologia, mas como pedra de toque da própria "filosofia da différance".

No que segue, vou me concentrar na análise de dois momentos da desconstrução de Husserl realizada por Derrida: 1. A desconstrução da teoria da expressão, que oculta, para Derrida, o motivo da presença; 2. a teoria das significações ocasionais, que oculta, para Derrida, os motivos da estrutura e da morte.

\section{Dois momentos da desconstrução em A Voz e o Fenômeno}

\section{Expressão e índice}

Se eu digo algo, e.g., "o gato está no tapete", esse meu dizer possui duas funções: i. ele expressa o estado de coisas de que o gato está no tapete; ii. e indica para um interlocutor que eu tenho essa vivência particular de que o gato está no tapete (digamos, indica que eu estou pensando que o gato está no tapete). Para Husserl, essas duas funções são um tanto distintas (Husserl, 1984, p.30 ss.). A indicação é uma relação entre dois existentes: algo (no caso, o que eu disse) aponta (anzeichen)

2 "Não teríamos já o direito de dizer que toda a problemática futura da redução e todas as diferenças conceituais em que ela se expressa (fato/essência, transcendentalidade/mundanidade, e todas as oposições que com ela fazem sistema) se desdobram num desvio entre dois tipos de signos? Ao mesmo tempo em que ele, se é que não nele e graças a ele?” (Derrida, 2012, p.36, meu grifo). 
para a existência de um outro algo. Meu interlocutor não tem acesso direto à minha vivência: ele não vê meus pensamentos. Ele é, antes, levado à crença (Überzeugung) na existência da minha vivência, assim como a fumaça nos leva a crer na existência de fogo (idem, p.32). Minhas vivências são a ele manifestadas. Com a expressão, passa-se de outro modo. O estado de coisas expresso não é necessariamente um existente (posso expressar um centauro, um quadrado redondo etc.), e a relação entre meu dizer e aquilo que expressei pelo meu dizer não é uma relação de um apontar indicativo: não sou levado a crer na existência daquilo que eu disse, pois um crer de tal tipo seria inútil (zwecklos), segundo Husserl (idem, p.43). Ao dizer algo, aquilo que eu disse é dado, para mim mesmo, no mesmo instante (im selben Augenblick) em que eu o disse (idem, ibidem).

O objetivo de Husserl nas Investigações Lógicas é a análise descritiva da relação entre a subjetividade do conhecer e o objeto do conhecimento (idem, p.13). Portanto, o estudo dos atos comunicacionais (aqueles que implicam índices e o apontar entre signo e o existente designado pelo signo) não é, ali, de seu interesse. Interessa, antes, a relação entre aqueles estados de coisas expressos e sua (re)instanciação em atos distintos de expressão. Ou seja, aquilo que a expressão expressa pode ser novamente expresso em atos separados no tempo; já aquilo que eu indico (minha vivência concreta particular), não (idem, pp.108, 109). Esses estados de coisas expressos são considerados, por Husserl, significações ideais (idem, p.106), na medida em que não se identificam com os atos particulares de expressão: os atos particulares cessam no tempo, aquilo que é expresso por eles permanece e pode ser novamente instanciado por atos subsequentes. Disso se segue a necessidade de uma "redução" metodológica a um âmbito no qual essa relação entre atos de expressão e significações ideais expressas possa ser investigada. Tal será o âmbito da "vida solitária da alma", onde o sujeito fala a si mesmo e, portanto, não necessita de "mediações" entre aquilo que fala e aquilo que é expresso pela fala (idem, p.41 ss.).

É aqui que Derrida enxerga um primeiro indício do compromisso husserliano com a metafísica da presença. Há, na vida solitária da alma, um "laço de essência entre o logos e a phoné” (Derrida, 2012, p.19): a voz é indiscernível da significação que ela expressa. 0 índice, que trazia sempre um desvio, uma mediação, deve ser abstraído - e isso significa, para Derrida, excluído. O recuo à vida solitária da alma é o recuo a um espaço privilegiado onde aquilo que eu expresso é vivido, por mim, no mesmo instante em que o expresso: "Está implicado na própria estrutura da fala que o falante se ouça [le parleur s'entende] (idem, p.85)”. Eis a definição do ser como presença: "Proximidade absoluta da identidade a si, estar-diante do objeto disponível para repetição, manutenção do presente temporal cuja forma ideal é a presença a si da vida transcendental, cuja identidade ideal permite idealiter a repetição até ao infinito" (idem, p.106). "Proximidade absoluta”: a significação expressa não 
necessita do apontar indicativo - ela é vivida por mim no mesmo instante. "Estardiante do objeto disponível para repetição": a significação expressa é aquilo que é e pode ser indefinidamente repetida em atos de expressão distintos. "Presença a si da vida transcendental": a consciência que funciona como médium para aquilo que é conhecido não é a consciência mundana (atrelada à existência, portanto à relação de indicação), mas deve ser uma consciência cuja voz é “fenomenológica”.

Derrida interpreta o empreendimento husserliano como a tentativa de conciliação de dois motivos: "a pureza do formalismo e a radicalidade do intuicionismo" (idem, p.21). 0 "princípio de todos os princípios" é sempre evocado: "toda a intuição doadora originária é uma fonte de direito para o conhecimento; tudo o que se nos oferece na 'intuição' de modo originário (na sua realidade corporal, por assim dizer) deve ser simplesmente aceite pelo que é dado, mas também sem ultrapassar os limites nos quais ele se dá então" (Husserl apud Derrida, idem, p.68). A fenomenologia parte do dado presente em sua imediaticidade, e as demais formas de doação são derivadas desta presença absoluta. Essa presença é imediatamente associada, por Derrida, ao presente temporal ${ }^{3}$ : a legitimidade da presença envolve sua capacidade de ser repetida indefinidamente como a mesma, i.e., como idêntica, em diversos atos que se estendem no tempo. A idealidade (presença) implica, portanto, a repetição no tempo (presente). O locus dessa repetição é, claro está, a consciência que é, também, presente a si (a voz que "se ouve" [s'entende]).

A desconstrução começa quando Derrida questiona esse status derivativo da não-presença, do índice, da linguagem. Como enfatizado várias vezes ao longo do texto, "é o próprio Husserl que nos dá os meios para contra ele mesmo pensar" (Derrida, idem, p.57). É crucial sublinhar que Derrida nada tem contra o caráter ideal das significações husserlianas:

Um signo que só tivesse lugar "uma vez" não seria um signo. Um signo puramente idiomático não seria um signo. [...] Um fonema ou um grafema é necessariamente sempre outro, em certa medida, cada vez que se apresenta numa operação ou numa percepção, mas só pode funcionar como signo e linguagem em geral se uma identidade formal permitir reeditá-lo e reconhecê-lo. Esta identidade é necessariamente ideal (idem, p.57, meu grifo).

Até aqui, temos, como bem indicado por Mulligan (1991, p.202), uma fiel descrição do "primeiro platonismo" de Husserl. A crítica vem a seguir:

[Um signo] implica, portanto, necessariamente, uma representação: como Vorstellung, lugar da idealidade em geral, como Vergegenwärtigung, possibilidade de repetição reprodutiva em geral, como Repräsentation, enquanto cada acontecimento significante é substituto (tanto do significado como da forma ideal do significante) (Derrida, 2012, p.57).

3 Ver, a esse respeito, todo o Capítulo 5 de $A$ Voz e o Fenômeno. 
O que significa dizer que toda identidade de significação implica uma representação? 0 apoio textual parece ser a afirmação de Husserl de que, na vida solitária da alma, contentamo-nos com "representações ao contrário de palavras reais" (Husserl, 1984, p.42). Disso conclui Derrida que é indiferente, para o signo, ser instanciado em um ato de percepção ou em um ato de fantasia: "o signo é originariamente trabalhado pela ficção" (Derrida, 2012, p.63). Essa conclusão contém, segundo Derrida, uma "cadeia inteira de consequências temíveis para a fenomenologia" (idem, ibidem). Isso porque ela destrói qualquer possibilidade de distinção entre linguagem efetiva e linguagem fictícia, sendo que tal distinção é crucial para a separação entre expressão e índice - que, por sua vez, é a distinção "fundadora" da fenomenologia, na leitura de Derrida. Ou seja: a distinção entre expressão e índice pretendia mostrar que o sersigno é "estranho à presença a si do presente vivo", "estranho à presença em geral, naquilo que se julga poder reconhecer com o nome de intuição ou de percepção" (idem, p.65). 0 índice está presente na comunicação porque o dado está ausente; ele está ausente no monólogo interior, porque o dado está absolutamente presente. No monólogo, o índice é inútil, Zwecklos: "Esta Zwecklosigkeit da comunicação interior é a não-alteridade, a não-diferença na identidade da presença como presença a si" (idem, ibidem). Ora, ao mostrar que toda identidade de significação implica uma representação (no sentido de uma "simples representação", "fantasia"), Derrida está trazendo a alteridade para o interior do monólogo - ou seja, está implicando a alteridade no espaço da não-alteridade por excelência, que é o espaço da vida solitária da alma: "esta alteridade é mesmo a condição da presença, da presentação e, portanto, da Vorstellung em geral, antes de todas as dissociações que nela se poderiam produzir" (idem, p.72). Essa alteridade receberá, finalmente, o nome de différance. É, segundo a definição, aquela diferença radical que está na origem da própria concepção de presença e presença a si:

em todas estas direções, a presença do presente é pensada a partir da dobra do retorno, do movimento de repetição, e não o inverso. 0 fato de tal dobra ser irredutível na presença ou na presença a si, o fato de este vestígio ou esta "différance" ser sempre mais velha do que a presença e lhe facultar a sua abertura, não proibirá que se fale de uma simples identidade a si "im selben Augenblick"? (idem, p.74).

\section{Percepção e significações ocasionais}

O segundo ponto da desconstrução de Husserl parte da teoria das "expressões essencialmente ocasionais". Tal é o nome que Husserl confere para os dêiticos: aqueles termos cuja significação é vinculada ao tempo e espaço. Só posso compreender a significação de termos como "aqui", "agora", "eu” etc., no interior de um contexto e de uma situação. Derrida se concentra no tratamento dado à expressão ocasional "eu". Segundo Husserl, "a palavra eu nomeia, consoante os casos, uma pessoa 
diferente e fá-lo por intermédio de uma Bedeutung sempre nova", e "quando lemos esta palavra sem saber quem a escreveu, temos uma palavra, se não desprovida de Bedeutung, pelo menos estranha à sua Bedeutung normal” (Husserl apud Derrida, idem, p.102). Aqui, novamente, Derrida nos diz que "as premissas de Husserl deveriam autorizar-nos a dizer exatamente o contrário" (Derrida, idem, ibidem). As premissas husserlianas, nesse caso, são aquelas da tese da distinção entre significação e objeto e da teoria da significação da percepção. A distinção entre significação e objeto encontra-se, pela primeira vez, no $\$ 12$ da Primeira Investigação. Ali, Husserl nos diz que "dois nomes podem significar coisas diferentes, mas nomear o mesmo" (Husserl, 1984, p.53). Assim, "O vencedor de Jena" e "O vencido de Waterloo" são duas significações distintas que nomeiam o mesmo objeto (Napoleão). Já a teoria da significação da percepção é aquela apresentada no §4 da Sexta Investigação e que sustenta que uma expressão, e.g., "esse animal negro voa alto", pode permanecer a mesma, ainda que a percepção varie (o animal continue voando) (idem, p. 550). Logo, a significação (que é idêntica) da expressão não pode residir na percepção que se alterna.

Assim como significação e objeto são interdependentes, e assim como a significação de uma percepção não reside na percepção, assim também, prossegue Derrida, a significação do eu não pode ser identificada a este eu. Antes, "não tenho necessidade da intuição do objeto Eu para compreender a palavra Eu" (Derrida, 2012, p.102). Segundo Derrida, "só isso permite explicar o fato de compreendermos a palavra Eu não só quando o seu 'autor' é desconhecido, mas quando é perfeitamente fictício. E quando está morto” (idem, p.103). Disso conclui (!) Derrida que "a minha morte é estruturalmente necessária ao pronunciar o Eu. Que eu também esteja 'vivo' e de tal tenha a certeza é algo exterior ao querer-dizer" (idem, ibidem).

Ao aplicar a premissa geral da teoria (normal) da significação ideal de Husserl ao caso específico (anormal) das expressões ocasionais, Derrida acredita ter mostrado, mais uma vez, que o imperativo da presença comanda o sistema de distinções husserliano. Segundo Derrida, o que leva Husserl a não aceitar o significado do eu como a-contextual é o mesmo motivo que o leva a privilegiar as leis da significação frente às leis da gramática pura lógica. Numa palavra, trata-se do motivo do logocentrismo. A gramática pura lógica é a teoria que fixa os limites do discurso enquanto discurso significativo. Ela rege as formas puras de construção de um discurso com sentido, não se importando, portanto, com a possibilidade da intuição daquilo que é expresso pelo discurso. Segundo tais leis, "o círculo é quadrado" é um discurso com sentido (sinnvoll), enquanto "a é ou zebra amém", não. Essas leis fazem abstração da "validade objetiva" do discurso, atendo-se à sua possibilidade. As leis que, por sua vez, dão conta da validade objetiva do discurso, são as leis da significação. Segundo estas últimas, o discurso pode ter sentido (sinnvoll), mas ser um 
contrassenso (Widersinn) (Husserl, 1984, pp.334 ss.). É o caso do "círculo quadrado", que possui sentido (eu compreendo a expressão), mas é um contrassenso, na medida em que não é passível de preenchimento intuitivo. Segundo Derrida, essa distinção entre gramática pura lógica e leis da significação "apaga a emancipação do discurso como não-saber [que era proporcionado pela gramática pura lógica]" (Derrida, 2012, p.104). "É decerto possível falar ao dizer que o 'círculo é quadrado', fala-se bem ao dizer que não existe" (idem, ibidem). $E$ isso significa que "o verdadeiro e autêntico querer-dizer é o querer dizer-a-verdade" (idem, ibidem). ${ }^{4} 0$ mesmo se passaria no caso das expressões essencialmente ocasionais, como eu. Segundo Derrida, a "normalidade" que Husserl confere ao discurso do "eu" quando se sabe quem está falando, e seu caráter "anormal" quando este é desconhecido, é sinal desse privilégio da lei da significação (que se preocupa com o preenchimento intuitivo do discurso) ante o discurso puramente possível (que se preocupa somente com sua "forma"). Em suma, "a originalidade do querer-dizer como intento é limitada pelo telos da visão" (idem, ibidem).

Todos esses motivos são, por fim, interligados: "só uma relação com a minhamorte pode fazer surgir a différance infinita da presença” (idem, p.108). Traduzamos. Husserl dirá que a flutuação das significações ocasionais é um atributo subjetivo delas (Husserl, 1984, p.86). Objetivamente, seria sempre possível reduzir tais significações a uma univocidade ideal. Tudo que é, é "em si", e pode ser conhecível "em si", independente, portanto, do contexto. Tal é o princípio da "ausência de limites da razão objetiva" (idem, p.95). Husserl dirá, porém, que tal redução "não é realizável de fato e que, inclusive, será sempre irrealizável" (Husserl apud Derrida, 2012, p.107). Mais ainda, dirá que "estamos infinitamente longe deste ideal [da razão objetiva]" (Husserl apud Derrida, idem, ibidem). Disso conclui Derrida que todo o sistema de distinções husserliano (entre signo e não-signo, idealidade e nãoidealidade, sujeito e objeto, intenção e intuição, mundano e transcendental etc. etc. etc.) que, lembremo-nos, enraíza-se na distinção entre expressão e índice, é "diferida até ao infinito" (Derrida, idem, p.106). Isto quer dizer: "de fato, realiter, nunca são respeitadas, como Husserl reconhece. De direito e idealiter, desvanecemse, pois só vivem, como distinções, da diferença entre o direito e o fato, a idealidade e a realidade. A sua possibilidade é a sua impossibilidade" (idem, pp.107, 108). Segundo Derrida, ao atrelar a possibilidade de pensar um "eu descontextualizado" a um "ideal infinitamente longe", Husserl está atrelando a finitude à infinitude (uma vez que um eu descontextualizado nada mais é que um eu morto). ${ }^{5}$ Isso coloca-nos,

40 fato de haver toda uma Investigação dedicada à Gramática Pura não depõe contra essa afirmação de Derrida de que Husserl se interessa pela linguagem "apenas no horizonte da racionalidade" (Derrida, 2012, p.13)?

5 Perceba como Derrida se utiliza de uma expressão metafórica de Husserl para extrair conclusões filosóficas. Isso me parece um traço claro do modelo desconstrutivo de leitura: perguntar-se pelo 
inarredavelmente, na posição de sempre fazer derivar a diferença. Isso, para Derrida, mostra, por parte de Husserl, um "hegelianismo ainda mais radical” (que o do próprio Hegel), pois é "por excelência no ponto em que mostra que o infinito positivo deve ser pensado (o que só é possível se ele se pensar a si próprio) para que a indefinidade da différance surja como tal" (idem, p.108). Para pensar na possibilidade da nãoexistência (na significação do eu como implicando sua morte), preciso pensar no “infinito positivo", que é como Derrida interpreta o ideal da ausência de limites da razão objetiva (que é um "ideal infinitamente longe"). A esse hegelianismo radical contrapõe Derrida o discurso sobre a minha-morte:

o próprio aparecimento da différance infinita é finito. Portanto, a différance, que não é nada fora desta relação, torna-se a finitude da vida como relação essencial a si com à sua morte. A différance infinita é finita. Já não é possível, pois, pensá-la na oposição entre a finidade e a infinidade, entre a ausência e a presença, entre a negação e a afirmação (idem, ibidem).

O corolário dessa desconstrução é considerar "normal” aquilo que Husserl julgava ser "anormal”, qual seja: a situação do "eu” anônimo, cuja possibilidade está condicionada à "nunca realizável”, à “infinitamente longe" recondução da flutuação das significações subjetivas e ocasionais à significação ideal e objetiva. 0 primário, portanto, não é o dado, mas “a experiência da deriva indefinida dos signos como errância e mudança de cenas (Verwandlung), encadeando as presentificações (Vergegenwärtigungen) umas nas outras, sem princípio nem fim" [...] "a própria coisa subtrai-se sempre" (idem, p.110, tradução modificada).

\section{Zurück zu Husserl}

\section{O signo e a coisa}

O que aconteceria se a interpretação de Derrida acerca da distinção entre expressão e índice não encontrasse sustentação no texto husserliano? Derrida escreve: “Husserl demonstrará que a remissão expressiva (Hinzulenken, Hinzeigen) não é a remissão indicativa (Anzeigen). Mas sobre o sentido do Zeigen em geral, que, apontando assim o invisível com o dedo, pode depois modificar-se para Hinzeigen ou para Anzeigen, nenhuma questão original é levantada” (idem, p.29). A ausência de uma questão original sobre o signo em geral tem o seguinte resultado: “Husserl, ao

que levou o autor a expressar determinada ideia com essas palavras e não outras. Husserl diz que "estamos, porém, infinitamente bem longe desse ideal" ["Aber von diesem Ideal sind wir unendlich weit entfernt"] (Husserl, 1984, p.96). Dificilmente um leitor comum (ou seja, um leitor que não se vale da "desconstrução" como método de leitura) veria nesse uso inocente do termo "infinito", utilizado tão somente para expressar o caráter não prático dessa redução das expressões ocasionais a uma determinação impessoal-objetiva, algum sinal do conceito hegeliano de infinito. 
escolher por tema a logicidade da significação, julgando poder já isolar o a priori lógico da gramática pura no a priori geral da gramática, empenha-se resolutamente numa das modificações da estrutura geral do Zeigen: Hinzeigen, e não Anzeigen" (idem, p.28). Isso é textualmente falso. Como nos lembra D’Angelo (2019, pp.37 ss.), já nas primeiras páginas da Semiótica, de 1890, encontramos uma definição do conceito de signo em geral que revisa a primeira concepção husserliana de signo da Filosofia da Aritmética e que será posteriormente desenvolvida nas Investigações Lógicas. Eis como o signo é ali definido: "o conceito de signo é precisamente um conceito relacional (Verhältnisbegriff), ele remete (weist hin) para um designado" (Husserl, 1970, p.341). Ou seja, o signo é definido como um Hinweis que pode, então, funcionar como o Anzeige do Anzeichen ou como o expressar da Ausdruck. Além disso, se ainda é possível questionar se na Semiótica Husserl continua compreendendo o signo como substituto, nas Investigações é certo que não o é6: o signo é uma relação dinâmica de remissão à coisa, e por isso mesmo é constitutivo do próprio objeto da percepção7 (não fazendo sentido, portanto, falar em “pura presença” na percepção externa).

Se quisermos nos manter no texto das Investigações, encontraremos uma distorção explícita do texto husserliano que influencia toda a análise derridiana do índice no Capítulo 2. ${ }^{8}$ Eis como se dá a descrição husserliana do índice na Primeira Investigação: no \$2, Husserl define o índice como a relação de motivação nãointelectiva (nichteinsichtiges Motiv) entre A e B; no $\$ 3$ dirá que, deste modo, a "situação fenomenológica está relatada de modo tão geral que ela compreende tanto - Hinweisen do Anzeige quanto o Beweisen da dedução e fundamentação rigorosas" (Husserl, 1984, p.32). No caso da demonstração, dirá Husserl que não falamos de Zeichen ou Anzeigen (idem, p.33). Ou seja, Husserl primeiro discute o índice e o descreve como motivação não-intelectiva e depois afirma que essa discussão é ainda muito ampla, de modo que abarcaria ainda algo que não é o índice - nomeadamente, a relação de demonstração (que é uma motivação intelectiva). Derrida, no entanto, inverte a ordem do texto husserliano. Primeiramente, discute a "motivação em geral" (Derrida, 2012, p.34); depois, afirma que "Husserl define assim a comunidade de essência mais geral que reúne todas as funções indicativas" (idem, ibidem). Ou seja, a generalidade do discurso sobre a motivação (à qual Husserl aludiu para dizer que a motivação é mais que um mero índice, uma vez que ela pode também ser intelectiva) é, agora, imputada ao índice. Na leitura de Derrida, o índice é visto como abarcando dois tipos de motivação, intelectiva e não-intelectiva, e somente o

6 Como insinuado por Derrida em passagem já aqui citada (Derrida, 2012, p.57).

7 Cf. D’Angelo, 2020, p.80 ss. 0 trabalho de D'Angelo leva em conta não só o texto das Investigações, como também o texto da Umarbeitung da $6^{\text {a }}$ Investigação de 1913, apresentando, portanto, uma versão mais completa da concepção de signo das Investigações Lógicas.

8 Essa distorção foi notada por Evans, 1991, p.47. 
“índice no sentido estrito" (idem, p. 35) seria aquilo que Husserl realmente chama de índice. Eis que a inversão do texto husserliano serve como premissa para a conclusão de Derrida: "na ordem da significação em geral, todo o vivido psíquico, sob a face dos seus atos, mesmo quando visam idealidades e necessidades objetivas, só conhece encadeamentos indicativos" (idem, ibidem, meu grifo). Tal conclusão não se segue, pois a demonstração não é um tipo de indicação: não é como se o Beweis fosse índice no "sentido lato" e o Hinweis índice no "sentido estrito". No caso das necessidades objetivas que subsistem entre idealidades, o que está em jogo não é um tipo de relação indicativa, mas algo completamente distinto do índice: uma intelecção que visa uma conexão ideal dos juízos. Se houver a insistência de que devemos dar um crédito a Derrida e não considerar que sua intenção primeira é a de ser fiel à letra do texto do Husserl, deveremos, então, encontrar em outro lugar (que não o texto de Husserl que ele se propôs analisar) uma justificativa para essa afirmação de que também no caso das idealidades só o que temos são "encadeamentos indicativos". Mas, de acordo com os próprios princípios da desconstrução que vimos acima, o trabalho crítico deve partir do interior do texto. Não vejo como uma inversão da ordem do texto possa ainda ser vista como uma leitura legítima provinda de seu interior, habitando suas estruturas. Como diz Evans (1991, pp.174, 175):

a história de Derrida deve ser independentemente plausível, e é difícil ver como isso pode ser estabelecido, ainda que se escolha nunca se referir aos textos de Husserl. A razão para isso é que, em $A$ voz e o Fenômeno, Derrida é cuidadoso em não oferecer qualquer argumento independente para suas conclusões. Toda a estratégia de desconstrução do livro é permitir que o argumento se desenvolva estritamente e somente da leitura de Husserl. ${ }^{9}$

Uma inversão da ordem expositiva do texto não me parece, portanto, mesmo seguindo ao máximo o princípio de caridade, tão inofensiva para a interpretação de Derrida.

\section{O signo e a morte}

Vimos que a aplicação da teoria da significação "normal” de Husserl à teoria das significações ocasionais resulta, para Derrida, na conclusão de que "a minha morte é estruturalmente necessária ao pronunciar o Eu” (Derrida, 2012, p.103). Se pudermos reconstruir racionalmente seu argumento ${ }^{10}$, seria como segue:

9 Isso isolaria um pouco Derrida no que diz respeito à temática "filósofos lendo outros filósofos". Aristóteles pode ter distorcido Platão, mas as afirmações da metafísica aristotélica são independentes dessa distorção (e isso em geral parece válido para os demais: Schopenhauer lendo Kant, Heidegger lendo Husserl etc.).

10 Se a desconstrução de Derrida está blindada a uma "reconstrução racional", então dever-se-ia deixar claro qual tipo de abordagem crítica ela permite. Em todo caso, no argumento aqui em questão, não me parece que Derrida foi além dos limites de uma simples dedução lógica, o que, quero crer, autoriza-nos a submeter sua conclusão à crítica. 
1. A compreensão da significação é independente da intuição;

2. A compreensão da significação “eu” é independente da intuição;

3. Ora, o "eu” sem intuição nada mais é que um eu morto;

4. Logo, a compreensão do "eu” pode se dar mesmo com este "eu” morto;

5. LOGO, a morte do eu é estruturalmente necessária para a compreensão do eu.

O que autoriza a inflação modal de 4 para 5?"11 As "premissas husserlianas" poderiam, com muita caridade, ser aplicadas até 4 , mas certamente não até 5 . E o que exatamente Derrida quer dizer com "necessidade estrutural"? No texto não encontramos qualquer precisão desse conceito. É importante questionar a consistência desse ponto da desconstrução de Derrida, uma vez que ela parece jogar um papel crucial na sua própria filosofia. Ou seja, essa conclusão servirá de premissa para sua própria concepção, como se pode ver na seguinte passagem:

A ausência da intuição - logo, do sujeito da intuição - não é apenas tolerada pelo discurso, é requerida pela estrutura da significação em geral, por pouco que a consideremos em si mesma. É radicalmente requerida: a ausência total do sujeito e do objeto de um enunciado - a morte do escritor ou/e o desaparecimento dos objetos que ele conseguiu descrever - não impede um texto de "querer-dizer". Pelo contrário, esta possibilidade faz nascer o querer-dizer como tal, dá-o a ouvir e a ler (Derrida, 2012, p.100).

Isso tudo se deixa condensar na frase que parece resumir a tese geral de Derrida sobre o signo: "a possibilidade do signo é esta relação com a morte” (idem, p.61). Como diz Mulligan (1991, p.206), o que autoriza essa preferência pela "morte" na determinação do signo? Uma das causas da morte, por exemplo, é a falta de oxigenação, ou o envenenamento. Deveríamos dizer, então, que a possibilidade do signo é a relação com o oxigênio, ou com o veneno ${ }^{12}$

Além disso, a tese geral que está por detrás dessa conclusão, a saber, a tese que "o sujeito não pode falar sem proporcionar a si mesmo uma representação", e que "não podemos, portanto, imaginar um discurso efetivo sem a representação de

11 Searle foi quem pressionou Derrida a precisar sua noção de modalização. Essa discussão está resumida em Mulligan, 1991, p.207.

120 argumento de Mulligan não é mera troça com Derrida, no estilo da troça que Russell faz com Hegel ao discutir o problema da referência da asserção "O atual rei da França é careca", quando Russell afirma que "os hegelianos, que amam uma síntese, provavelmente concluirão que ele usa uma peruca" (Russell, 1906, p.485). 0 argumento de Mulligan é puramente lógico. Não se trata, aqui, de uma discussão sobre a dimensão da finitude, sobre o significado simbólico da morte, se esta é meramente um fato material de desintegração química de um corpo que nada mais é que um "agregado infeliz de sangue e cal" (Augusto dos Anjos), ou se é algo mais etc. Não é esse o debate. Trata-se, antes, de uma simples consequência lógica que se segue da noção de "relação". 
si” (Derrida, 2012, p.64), é tão antihusserliana quanto possível. Para Husserl, "quando fazemos, e.g., uma declaração, julgamos sobre a coisa correspondente, e não sobre a significação da frase declarativa" (Husserl, 1984, p.108). E, claramente, a tese central da primeira teoria da intencionalidade de Husserl é que a "representação de si" não acompanha o discurso efetivo: não há nenhum pensamento sobre meu eu e meus atos acompanhando meu pensamento sobre o objeto quando dele falo alguma coisa. ${ }^{13}$

\section{Conclusão}

As "premissas husserlianas", portanto, parecem não só insuficientes para as conclusões de Derrida, como parecem francamente desautorizá-las. Se isso tem alguma consequência para a própria filosofia de Derrida, não cabe aqui dizer: tal investigação exigiria um trabalho à parte sobre Derrida, e não sobre a leitura derridiana de Husserl. Acerca deste último ponto, que foi aqui nosso foco, certamente alguma consequência possui. Como vimos, Derrida nada tem contra o primeiro "platonismo lógico" de Husserl, segundo o qual "as significações formam [...] uma classe de conceitos no sentido de 'objetos gerais'” (Husserl, 1984, p.106). Trata-se da tese de que aquilo que é expresso pela expressão possui validade objetiva independente das vivências de atos que o expressam. Como vimos, segundo Derrida, "um signo que só tivesse lugar 'uma vez' não seria um signo" e "esta identidade [do signo] é necessariamente ideal" (Derrida, 2012, p.57). 0 que o permite fazer surgir a différance da "presença" na teoria da expressão de Husserl é sua compreensão de signo como a relação com a “minha-morte". Ora, esta compreensão só é possível a partir de uma acentuação do platonismo lógico, na medida em que o aplica também para o caso das significações flutuantes - aquelas cuja significação não possui validade objetiva independente, mas que são, ao contrário, dependentes do contexto da enunciação. Para Husserl, só se entende o que a palavra "eu" significa na presença daquele que expressa "eu". Para Derrida, o princípio husserliano da "ausência de limites da razão objetiva" deve nos autorizar a fixar uma determinação objetiva, platônica, para o "eu" - isto é, uma significação independente do contexto e da situação. Ali onde Husserl vê a presença do falante como essencial para a compreensão da palavra "eu", Derrida vê o contrário: "a minha morte é estruturalmente necessária ao pronunciar o Eu" (idem, p.103). Não é, portanto, exagero afirmar que o que conduz Derrida a atribuir a metafísica da presença a Husserl é um platonismo ainda mais intenso que aquele subscrito por Husserl à época das Investigações Lógicas. Que se veja, por exemplo, como Husserl aborda esse tema da redução das significações flutuantes-ocasionais à significação ideal-idêntica (platônica) segundo o princípio da ausência de limites

13 Cf., a esse respeito, Sartre, 2003. 
da razão objetiva: "removamos as palavras essencialmente ocasionais da nossa língua e tentemos descrever uma vivência subjetiva qualquer de um modo unívoco e objetivamente fixo. Qualquer tentativa é, obviamente, vã." (Husserl, 1984, p.96). Para Derrida, tal tentativa não só não é vã como é estruturalmente necessária, conforme nos mostra sua análise da expressão ocasional “eu”. Se Husserl representa, segundo Derrida, um hegelianismo mais radical que o do próprio Hegel, é com um platonismo mais radical que o do próprio Husserl que Derrida desvela os motivos entrelaçados da presença, da estrutura e da morte na teoria da significação das Investigações Lógicas.

Essa leitura derridiana pretende, como vimos, ser uma leitura "imanente" que opera "necessariamente do interior" do texto husserliano. Nessa sua leitura imanente, Derrida imputa a Husserl a tese de que há uma "comunidade de essência" entre signos cuja motivação é intelectiva e signos cuja motivação é não-intelectiva, subsumindo ambos os tipos de motivação sob um conceito "geral" de índice; conceito que teria no signo que funciona segundo a motivação não-intelectiva o sentido "estrito" de índice. Como vimos, essa conclusão de Derrida não se segue de uma leitura imanente, mas de uma inversão da ordem expositiva do texto husserliano - ou seja, de uma distorção do texto ${ }^{14}$. Husserl afirma o exato oposto do que Derrida lhe atribui, a saber, que "os dois conceitos [o Hinweisen da indicação e o Beweisen da dedução e fundamentação] devem certamente ser separados” (Husserl, 1984, p.32). Essa tese imputada a Husserl leva Derrida à conclusão decisiva de que "mesmo quando visam idealidades e necessidades objetivas, [todo o vivido psíquico] só conhece encadeamentos indicativos" (Derrida, 2012, p.35). Husserl afirma o contrário, a saber, que "a intelectividade [Einsichtigkeit] e, falando objetivamente, o conhecimento de uma conexão ideal dos conteúdos dos juízos relacionados estão aqui [na indicação] verdadeiramente excluídos” (Husserl, 1984, p.33), sendo estes, antes, marcas da demonstração que visa idealidades. Não há, portanto, qualquer “comunidade de essência" entre motivação intelectiva e motivação não-intelectiva que se deixaria entrever em um conceito de "índice em geral": se seguimos a correta ordem expositiva do texto husserliano, vemos que ambos os tipos de motivação devem ser radicalmente distinguidos.

Lembremo-nos que a intenção de Derrida é analisar a doutrina da significação de Husserl para encontrar motivos imanentes ao texto que nos permita subvertê-lo. Ora, pelo acima exposto, uma componente central dessa "análise" parece ser incapaz de servir como "premissa husserliana" para as conclusões de Derrida (conclusões que, estas sim, poderiam ir além do texto de Husserl), justamente porque não encontra fundamentação textual. Se o modelo desconstrutivo de leitura de textos

14 Apenas apontamos para essa distorção que já foi notada por muitos intérpretes. Para uma exposição minuciosa dessa distorção e suas consequências, cf. Evans, 1991, pp.46-55. 
deve "habitar" seu interior para então "ir além”, parece, nesse caso, ter falhado justamente no seu primeiro momento - o que colocaria em xeque o segundo.

Esse é, precisamente, o ponto a ser aqui salientado: Derrida insiste repetidamente que as "premissas husserlianas" nos levam a concluir o oposto de algumas teses do próprio Husserl - teses que, segundo Derrida, seriam fundantes e decisivas para toda a fenomenologia. No entanto, conforme tentamos aqui mostrar, se examinamos com atenção as análises derridianas responsáveis por apresentar tais "premissas", vemos que elas não são em absoluto premissas “husserlianas", uma vez que não se seguem do texto de Husserl (e, insista-se, Derrida pretende que sigam). Isso deveria pelo menos colocar em dúvida tanto as "conclusões opostas" a Husserl que supostamente se seguiriam de tais análises derridianas quanto a cadeia de "consequências temíveis" para a fenomenologia. Esse foi o debate que pretendemos abrir ao confrontar as análises de Derrida com o texto de Husserl. ${ }^{15}$

\section{Referências}

Bernet, R. , \& Brown, W. (1982). Is the Present Ever Present? Phenomenology and the Metaphysics of Presence. Research in Phenomenology, 12, 85-112. DOI: https:// doi.org/10.1163/156916482X00062

D’Angelo, D. (2019). Zeichenhorizonte: Semiotische Strukturen in Husserls Phänomenologie der Wahrnehmung. [S.l.]: Springer.

Derrida, J. Gramatologia. (1973). Tradução de Miriam Schnaiderman e Renato Janine Ribeiro. São Paulo, SP: Perspectiva.

Derrida, J. (1991). Margens da Filosofia. Tradução de Joaquim Torres Costa e António M. Magalhães. Campinas, SP: Papirus.

Evans, J. C. (1991). Strategies of deconstruction: Derrida and the myth of the voice. Minneapolis/Oxford: University of Minnesota Press.

Derrida, J. (2012). A Voz e o Fenômeno: introdução ao Problema do Signo na Fenomenologia de Husserl. Tradução de Maria José Semião e Carlos Aboim de Brito. Lisboa: Edições 10.

Husserl, E. (1984). Logische Untersuchungen. Untersuchungen zur Phänomenologie und Theorie der Erkenntnis. Hua XIX. Dordrecht: Kluwer Academic Publishers.

Husserl, E. (1970). Zur Logik der Zeichen (Semiotik). In . Philosophie der Arithmetik. Mit ergänzenden Texten (1890-1901). Hua XII. Denn Haag: Martinus Nijhoof.

Mulligan, Kevin (1991). How not to read: Derrida on Husserl. Topoi 10 (2):199-208. DOI: https: //doi.org/10.1007/BF00141340

15 Uma primeira versão desse texto foi apresentada na forma de seminário para o Grupo de Estudos de Fenomenologia da USP (GEFen-USP/CNPq). Agradeço a todos os presentes pela acirrada discussão ali promovida. Agradeço, também, aos pareceres anônimos desta revista pelas ótimas sugestões. 
Russell, B. (1905). On Denoting. Mind, 14(56), new series, 479-493. DOI: https://doi. org/10.1093/mind/XIV.4.479

Sartre, J. P. (2003). Une idée fondamentale de la phénoménologie de Husserl: l'intentionnalité. La transcendance de l'Ego et autres textes phénoménologiques. Paris: Vrin. 